But what form could such a consideration take? If the story of the remarkable conjunction of events that led to the discovery of penicillin were recounted to a philosopher, what could he say except "Why, gee, what amazing strokes of luck!"'. If Beveridge himself were a little more philosophical about the matter, he would see that there is an inherent bias in our estimate of the contribution of good fortune to scientific research: we can all recognize when good fortune leads to a discovery or enlarges the understanding, but from the very nature of things we cannot know how often bad luck deprives us of the chance of making a discovery we might otherwise have made.

The most interesting paragraphs in Beveridge's book are those in which he deals with various expedients for promoting the flow of original ideas. Not all are convincing: the more I read and reflect upon the virtues of "lateral thinking', the more I wonder what all the fuss is about. To be sure, we should all try to be adventurous in our thinking and try to get out of familiar ruts; but this is advice such as Polonius might have given - it cannot come to anyone as a revelation.

Beveridge criticizes Popper, as others have, for failing to throw much light on the process of ideation - the process by which new hypotheses come into being. Popper rebuts this charge perfectly adequately by pointing out that his work is mainly upon the logic of scientific discovery, and that ideation is outside logic and is a logically unscripted process. However Popper is fully aware of the central importance of having ideas as the generative act in scientific enquiry. In spite of Beveridge's criticisms I believe him to be more indebted to Popper than he realizes. In his final chapter, for example, he is clearly feeling his way towards the concept that Popper embodied in the notion of a "Third World" (Popper's Third World; see Nature 241, $293 ; 1973)$, though Beveridge clothes it in the tiresome terminology of 'hardware' and 'software' - an inappropriate terminology in this context because many ideas and conceptions are embodied in hardware such as machinery, buildings, institutions and so on.

One of the passages in which Beveridge seems to lack philosophic understanding is that in which he deals with frauds. In recounting the Piltdown hoax, brought up to date by incorporating Stephen Jay Gould's suggestion that the principal conspirator was none other than Teilhard de Chardin, he says that its main interest is to show "that even the scientific Establishment can be fooled by evidence that in retrospect is seen to be an obvious fake"'; but does not Beveridge realize that science, like banking and government and - if that wise man Kenneth Clark is to be believed - civilization itself, rests upon confidence. When we go about our business we do not expect our colleagues and coworkers to be liars; nor do we scrutinize their statements with wary circumspection, in the manner of men on their guard. If we did so there would be no scientific business to transact. In going on to describe Paul Kammerer's fraud, Beveridge says Kammerer's views on the nature of inheritance were quite incompatible with those of neo-Darwinists "who believed that evolution was due solely to the selection of chance mutations that favour survival". This is a travesty of neo-Darwinism, but it would take too long to explain why.

Accounts of the Summerlin scandal and the fraud implicating Sir Cyril Burt pad out the book readably, but their inclusion may give a rather distorted picture of science to the young scientists who are among those to whom the book is addressed. I surmise - for there can be no proving such a statement - that for every scientist who fiddles his results there are a thousand who do not, and for every scientist who waxes fat on the proceeds of deception a thousand others spend sleepless nights and days of sick anxiety for fear that they have been guilty of a factual misrepresentation - or even, what does not matter nearly so much, of propounding an erroneous hypothesis.

". . . most eminent scientists I know do have a lively sense of humour" says Beveridge - a characteristic he chooses to

\section{Freudian variations}

\section{Stuart Sutherland}

Freud: The Man and the Cause. By Ronald W. Clark. Pp.652. (Cape/Weidenfeld \& Nicolson/Random House: 1980.) £9.95, $\$ 19.95$.

IMAGE
UNAVAILABLE
FOR
COPYRIGHT
REASONS

FrEUD was nearly 40 when he began to develop the psychoanalytic ideas for which he is remembered, but even as a youth he was convinced that he would be a famous man. From the age of 21 he periodically tried to dest roy all records of his private life in a deliberate attempt to make difficulties for his biographers, each of whom would "be right in his opinion of "The Development of the Hero'." The latest to take up Freud's challenge is a highly illustrate by referring to Waddington's witless and disagreeable acronym COWDUNG which stands for 'conventional wisdom of the dominant group'.

Beveridge has some wider views on science in education which I find as difficult to accept as many of those that relate to science itself. He writes that “. . . it would benefit everybody if the education of scientists included more studies in the humanities ....". I wonder: my own view, as ill-founded as his own, is that the young scientist who has not the initiative and the will to read books or listen to music or visit galleries will be bored out of his mind by lectures of the quality he is likely to receive on subjects such as "the English novel' or 'the origins of the Romantic movement in Germany'. It would be a different story, of course, if an Ernst Gombrich or Kenneth Clark were to be found on every campus; but what can be found on every campus are libraries, radio, television, records and enthusiasts eager to share their enthusiasms - all of which may help to enlarge human sensibilities or human understanding.

Sir Peter Medawar is Head of the Transplantation Biology Section, Medical Research Council's Clinical Research Centre, Harrow, Middlesex.

professional biographer, Ronald Clark, who has already tackled Einstein, J. B. S. Haldane and Bertrand Russell. Fortunately for Clark, Freud's correspondents did not always obey his injuction to destroy his letters and considerable new material has come to light since Ernest Jones wrote the mammoth official biography.

The standard view of Freud's life, as put forward by Jones and other followers, is that he was indeed a hero. They argue that his theories were for long either ignored or derided because of their shocking sexual content, he was denied promotion, he fought with the world in "splendid isolation", and psychoanalysis emerged almost entirely from his own head (or genitals) as a result of his heroic selfanalysis. Freud, himself, in his autobiographical writings did everything he could to encourage this view.

In recent years, several scholars have attempted to modify the myth of Freud's heroism. His ideas received considerable support almost from the outset; to the extent to which they were rejected, it was because they were old-fashioned (for example, his attribution of some neuroses to masturbation) or obviously wrong (for example, his belief that many neurotics had been sexually seduced in infancy by an older person). At no time was he isolated from the rest of the scientific community, and many of his ideas were either modifications of existing lines of thought 
or were developed in collaboration with others, particularly with Wilhelm Fliess with whom he was in regular correspondence throughout the period when he was developing the basic ideas of psychoanalysis. It is significant that despite their intimacy and the overlap in their work and ideas, Freud does not so much as mention Fliess in his autobiography, and he tried to have his letters to Fliess destroyed. The revisionist view of Freud's career is well summarized by Frank Sulloway in Freud: Biologist of the Mind (Deutsch, 1979) which was published too late to be of use to Ronald Clark in writing his own biography.

Clark takes a middle-line on these contentious issues. He concentrates on Freud the man rather than on the intellectual content and origins of his work. On Freud's personality there is little new to say. He was often tetchy and intolerant, as when he reproved his wife for talking to strangers in a restaurant. $\mathrm{He}$ could be extraordinarily vindictive: although he formed intimate friendships with several men (such as Breuer and Fliess) the friendships did not last and, once they were broken, Freud never forgave. $\mathrm{He}$ loudly proclaimed that psychoanalysis was a science, but he treated it as a religion: he was merciless to the many followers who dared to depart from the orthodox doctrine as laid down by himself. On defection, Morton Prince became "an arrogant ass", Magnus Hirschfeld "a flabby, unappetising fellow", and Carl Jung a "megalomaniac" and a "miserable pen-pusher". One wonders how much insight Freud had into his own childishly defensive reactions.

Another of Freud's persistent traits was that he took great delight in annoying others. Of his fiancée's mother, he wrote "I can foresee more than one opportunity of making myself disagreeable to her and I don't intend to avoid them". He stayed away from one neurological congress because "our absence should annoy them and that suits me"'. It is likely that Freud's failure to achieve rapid academic promotion was caused more by his own prickly personality than by his Jewishness or the unpopularity of his ideas.

His lust for battle and intellectual arrogance polarized opinion on psychoanalysis. He gave those who were not wholly for him no option but to be against. He made matters worse by his reluctance to admit his own mistakes: for example, he did not publicly disavow his infantile seduction theory until many years after he had himself abandoned it.

In contrast to his behaviour with friends, he seems at least in adulthood always to have been generous and kind towards both his immediate family and his more distant relations. But they would appear never to have crossed his wishes and to have treated him as their natural leader.

Perhaps Freud's greatest virtue was courage. In the last 16 years of his life, he had over 30 operations for cancer of the

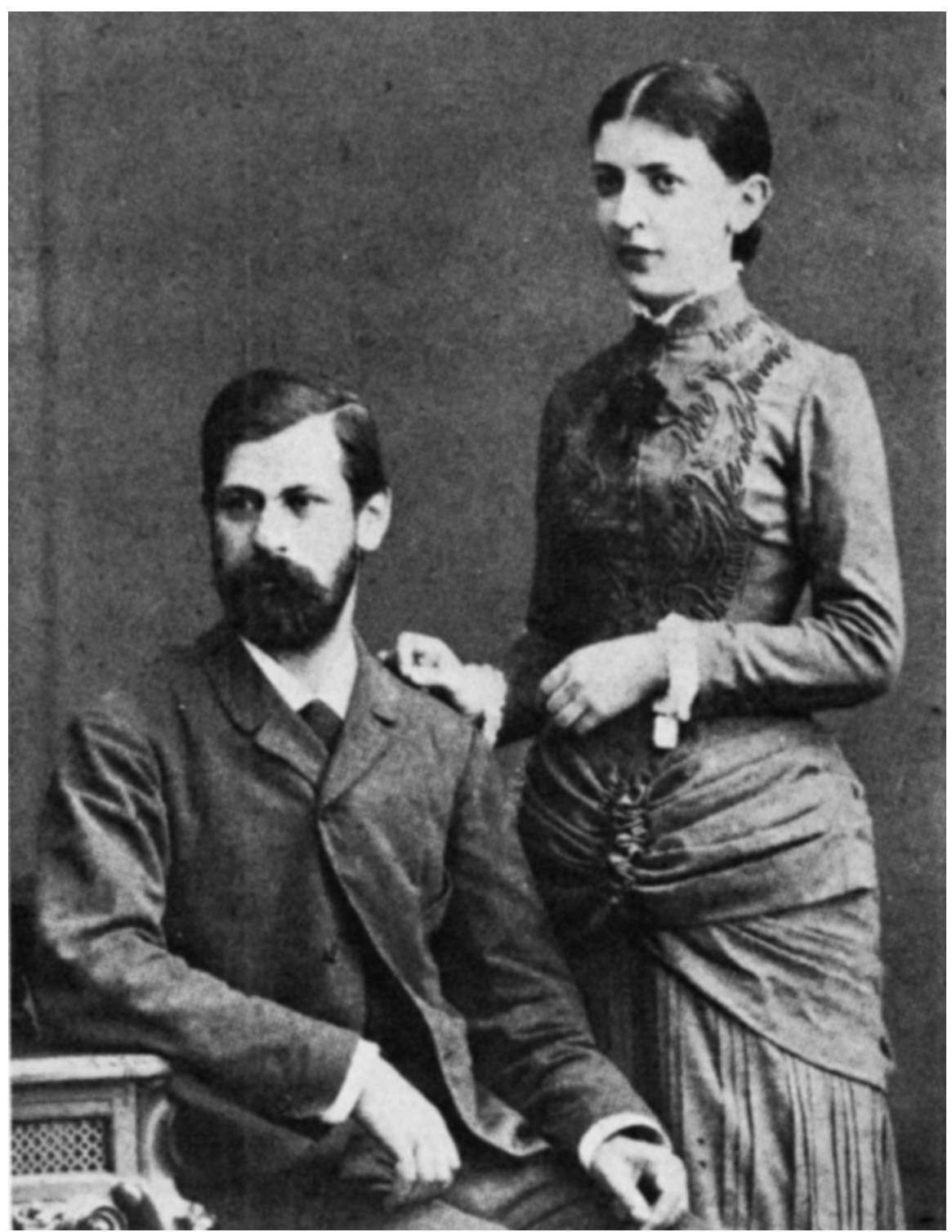

Freud and Martha Bernays, photographed in Wandsbeck, her home outside Hamburg, in 1885

mouth and had to wear an uncomfortable prosthesis. He bore the pain and danger with the greatest stoicism, continuing both his writing and his clinical work. When it became clear that he was dying, he calmly asked his doctor to plit him out of his suffering. In the face of all medical advice, he went on smoking large cigars to the end of his life.

Freud: The Man and The Cause records all this and much more, yet at the end of the book most readers will feel that they have not learned what Freud was really like: his own secrecy about himself and his determination to act the part of hero make it difficult to unravel the inner workings of his mind. Moreover Ronald Clark records events, but passes few judgements of his own.

Perhaps wisely, he neither interprets Freud's life in psychoanalytic terms, nor does he derive Freud's psychoanalytic ideas from his life. The clues to the latter problem are tantalizingly few: Freud had a doting mother; as a young man his attitudes towards the opposite sex were prudish; his friendships with members of his own sex were highly emotional; and he appears to have given up all sexual activity from the age of 41 , by which time he was in the midst of his own self-analysis.

Clark describes the elements of Freud's ideas clearly, but at an elementary level: his excellent index contains no reference to such terms as "displacement", "projection", "regression" or "polymorphous perversity". He makes little attempt to evaluate Freud's work and when he does he is often wildly wrong. For example, he attributes recent revisions of psychoanalytic theory to unspecified advances in biochemistry, and quotes with approval Bertrand Russell's silly criticism of Freud's theory of dreams that "we cannot know what a man dreams, but only what he says he dreams": as far as psychoanalytic theory is concerned, it is irrelevant whether the patient has actually dreamt something or merely thinks he dreamt it.

Clark cannot be altogether blamed for his failure to assess the importance of Freud's ideas. Psychologists still know so 


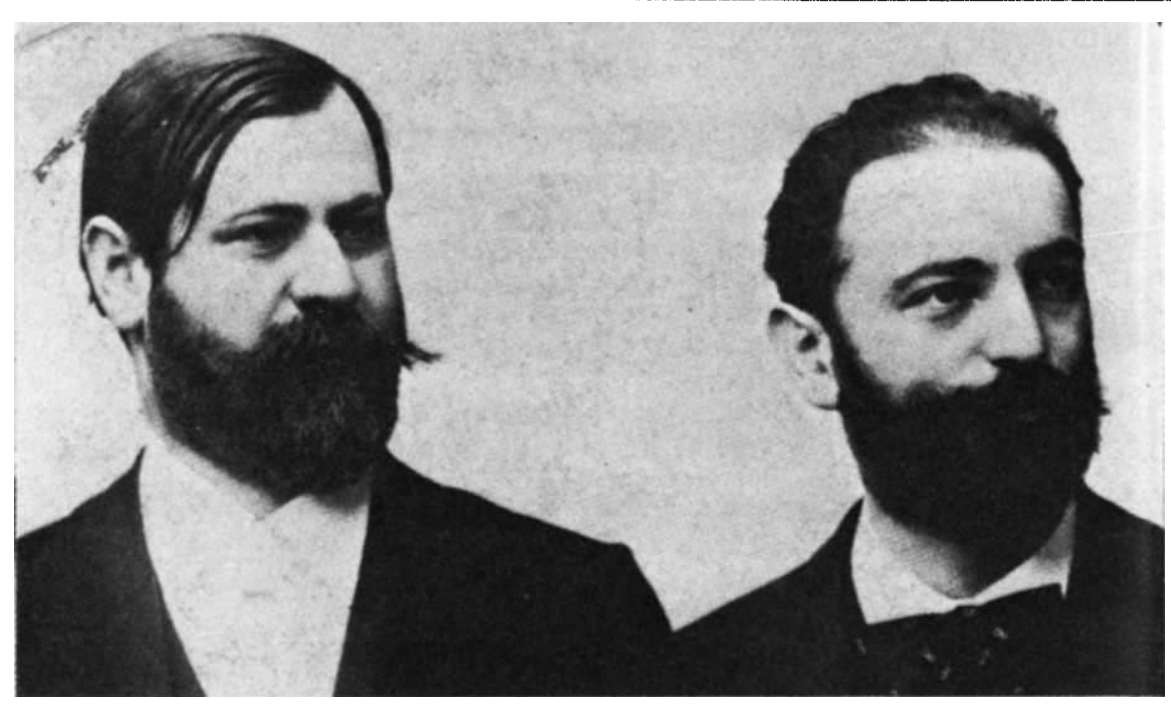

Freud (left) with Wilhelm Fliess, his confidant during the early years of psychoanalysis

little about the forces that motivate human action that the ultimate value of Freudian theory cannot be assessed. It is certain only that much of the theory remains vague and that Freud often overgeneralized: his concentration on the libido and the Oedipus complex as the main influences in the development of personality was mistaken. It is doubtful if present-day psychology would be much different had Freud never lived: his main influence has been on the patterns of thought of the layman and hence on much twentieth-century art and culture. Moreover, there are many who feel that Freud sent psychotherapy in a wrong direction, and that it has only recently

begun to recover from the damage done by his ideas. New therapeutic developments are much closer to Adlerian practice than to Freudian.

There are no pyrotechnics in Ronald Clark's new book, but he has made available in one place a mass of previously published material and has added some facts of his own discovery. Although he has not broken the enigma of Freud's personality, he has produced a highly professional biography.

Stuart Sutherland is Director of the Centre for Research on Perception and Cognition at the University of Sussex.

\section{What is it that we know?}

\section{D.V. Lindley}

\author{
The Enterprise of Knowledge: An Essay on \\ Knowledge, Credal Probability, and \\ Chance. By Isaac Levi. Pp.462. (MIT \\ Press: 1980.) $\$ 27.50, £ 17$.
}

A SUBSTANTIAL part of the knowledge of the world that we have today is the result of the activities of scientists. If knowledge is thought of as a tool by which we may control the world, then scientific thinking is pre-eminent. Artists may help our understanding, but it is scientists who develop the techniques and ideas of control. It is therefore surprising that scientists have paid so little attention to the appreciation of how knowledge is acquired and manipulated. Kuhn has pointed out that most scientific work consists of following through a standard set of techniques, or paradigms, and that the individual is so absorbed in the technicalities of the apparatus, the field, or the mathematics, that he never needs to think about the basis of what he is doing. Other scientists, a small but significant minority, do think more widely but again are statisticians and most philosophers now agree upon: the description of our knowledge, and the way that knowledge is used in control, are essentially probabilistic. There are, however, substantial differences on how probability is to be used and what it means. The accepted paradigm of statistics uses probability only in the sense of frequency, so that we may speak of the probability of the experimental results, which may be repeated, but not of the probability of the hypotheses, which cannot. A minority of statisticians, and perhaps the majority of philosophers, think of probability as a direct descriptor of knowledge, so that probabilities of hypotheses are admitted. Some think of this probability as subjective, some as objective. Here philosophy is providing usable, and - it is to be hoped - useful, results; scientists ought to take note.

In this book, Isaac Levi talks of what he chooses to call credal probability as the way of evaluating hypotheses. Knowledge is thought of, not as a collection of results, but as an input to rational decision-making _ "Epistemologists ought to care for the improvement of knowledge rather than its pedigree'". The same should be true of scientists. Levi is thus no scholar isolated from practice, but a scholar who is concerned with application as the basis of our thinking. (An appendix discusses the use of his ideas in assessing accident risks in nuclear power plants.)

He therefore disagrees with most statisticians' view of probability as only frequentist - in such situations he talks of "chance" - and devotes a fair portion of the book to a criticism of the methods they have developed, paying special attention to Fisher's concept of fiducial probability, a concept that exerts a fascination out of all proportion to its value. His view is the Bayesian one that probability applies to all uncertainty, not just to repeatable phenomena; so that we can speak of the probability of isolated events, or of hypotheses. What Levi calls a "strict" Bayesian, says this probability is unique and definite, and expresses the totality of our knowledge. In conjunction with utility (which receives little discussion in the book) decisions can be made by maximizing expected utility. Levi does not agree with this uniqueness and admits a set of probabilities. This leads to a difficulty, since the existence of many probabilities leads to many expected utilities, and choice between them has to introduce other considerations. He uses a maximin device in which the worst possible outcome is made as attractive as possible. (It is a pity he does not discuss the objections to maximin that exist, especially as he uses a restricted form of that criterion to which they may not apply.)

Levi writes as a philosopher and the emphasis in his treatment is on the ideas rather than their execution. He discusses at length the related ideas of other 